\title{
Prevalence of Hepatitis C Virus Genotypes in Iranian Patients: A Systematic Review and Meta-Analysis
}

\author{
Mazaher Khodabandehloo ${ }^{1,2,} ;$ Daem Roshani ${ }^{3}$ \\ ${ }^{1}$ Department of Microbiology, Faculty of Medicine, Kurdistan University of Medical Sciences, Sanandaj, IR Iran \\ ${ }^{2}$ Cellular and Molecular Research Center, Kurdistan University of Medical Sciences, Sanandaj, IR Iran \\ ${ }^{3}$ Social Determinants of Health Kurdistan Research Center, Kurdistan University of Medical Sciences, Sanandaj, IR Iran \\ ${ }^{*}$ Corresponding Author: Mazaher Khodabandehloo, Department of Microbiology, Faculty of Medicine, Kurdistan University of Medical Sciences, P. O. Box: 6617713446, Sanandaj, IR \\ Iran. Tel: +98-8731827292, Fax:+98-8733664674, E-mail: mazaher-kh@muk.ac.ir
}

Received: August 19, 2014; Revised: November 9, 2014; Accepted: November 9, 2014

\begin{abstract}
Context : Hepatitis C virus (HCV) is a global public health problem and a major etiology of chronic liver disease, which may develop into cirrhosis and hepatocellular carcinoma. Genotypes of HCV indicate the route of acquisition, the clinical outcome, response to treatment, prognosis and control strategies.

Objectives: The aim of this study was to estimate the overall prevalence and trend of HCV genotypes or subtypes in Iran

Data Sources: A literature review was done for papers reporting HCV genotypes in Iranian patients in PubMed, Magiran, IranMedex, Scientific Information Databank, and Google scholar databases.

Study Selection: Data were selected according to inclusion and exclusion criteria.

Data Extraction: Data were abstracted by two independent authors. Data were analyzed based on random-effects model using the Meta R. Pooled statistical software. Prevalence of HCV genotypes in cities and provinces of Iran with 95\% confidence interval(CI) were calculated. Results: Fifty-three articles published between 1999 and 31 June 2014 including 22952 HCV infected individuals were included in the metaanalysis. Subtype 1a was predominant with a rate of 39\%(95\% CI: 34-44\%); followed by subtype 3a, 32\% (95\% CI: 26-39\%); subtype 1b, 13\% (95\% CI:10-15\%); genotype 4, 5.18\%(95\% CI:3.27-7.5\%); and genotype 2,3.6\%(95\% CI:1.6-8.3\%). Untypeable HCV had a rate of 0.11\% (95\% CI: 0.07-0.16\%). Conclusions: The most frequent subtypes of HCV in Iran were $1 \mathrm{a}, 3 \mathrm{a}$ and $1 \mathrm{~b}$, respectively. This frequency differed in various provinces of Iran and fluctuated with time. It is important to determine the distribution of HCV genotypes in different geographical areas and its trend with time for epidemiological and patients' management purposes.
\end{abstract}

Keywords:Hepatitis C virus; Genotypes; Molecular Epidemiology; Iran

\section{Context}

Hepatitis $\mathrm{C}$ virus (HCV) is a global public health problem. About 170 million people, nearly 3\% of the world's population, are chronically infected and at risk of developing liver diseases including cirrhosis and hepatocellular carcinoma. It has been estimated that three to four million are newly infected and 350000 deaths occur each year due to all HCV-related diseases. Liver dysfunction by HCV infection is one indication for liver transplantation. No vaccine or immune-globulins are available for prevention. Low effectiveness and high cost of the current antiviral drugs limit the treatments of HCV infection $(1,2)$.

Nowadays the most common route of HCV transmission is through syringe sharing among intravenous drug users (IVDUs) with a prevalence rate of 31 to $89 \%$ in different geographical areas of the world. Risk of infection in some groups such as, patients on hemodialysis, hemophilia, infants of mothers with HCV infection, and multi-partner individuals is very high. Prevalence of HCV among patients on hemodialysis was $5.5 \%$ to $55.9 \%$ in different cities of Iran, although this number for patients with hemophilia was 15.65 to $76.7 \%$ (3). The rate of HCV positivity among IVDUs was 52\% in Tehran (4).
According to a recently conducted meta-analysis, the overall prevalence of HCV among blood donors in Iran's provinces and cities was 0.5\% (95\% CI: 0.4-0.6\%). The highest prevalence of HCV was in Kashan (1.09\%), and the lowest prevalence was in South Khorasan (0.03\%). Hepatitis $C$ virus prevalence had a decreasing trend over 11 years. The highest prevalence rate was $1.39 \%$ in 2005 ; then, the prevalence rate had a decreasing trend to $0.13 \%$ in 2007 and $0.03 \%$ in 2009 (5).

In Iran HCV prevalence in the general population is significantly lower when compared to the corresponding populations in surrounding countries such as Afghanistan (1.1\%), Pakistan (4.7\%) (6), Turkey (1.0-2.1\%), Kuwait $(0.8 \%)$ and $\operatorname{Iraq}(7.1 \%)(7)$.

Hepatitis $C$ virus is a small, enveloped virus that belongs to the genus Hepacivirus and the family Flaviviridae. The diameter of the virion is about $55-65 \mathrm{~nm}$. The genome of HCV is a positive single-stranded RNA molecule of approximately $9.6 \mathrm{~kb}$. It encodes a polyprotein from a single open reading frame flanked by two untranslated regions (UTR) at the 5' and 3' ends of the genome. This polyprotein precursor is cleaved by proteases giving rise to structural

Copyright (C) 2014, Kowsar Corp. This is an open-access article distributed under the terms of the Creative Commons Attribution-NonCommercial 4.0 International License (http://creativecommons.org/licenses/by-nc/4.0/) which permits copy and redistribute the material just in noncommercial usages, provided the original work is properly cited. 
(Core, glycoproteins E1, E2) and nonstructural proteins (NS2, NS3, NS4A, NS4B, NS5A and NS5B). The HCV genome has a high rate of mutations therefore genetic heterogeneity of $\mathrm{HCV}$ is observed in patients $(2,8)$.

Hepatitis $C$ virus is classified into seven major genotypes $(1,2,3,4,5,6$ and 7$)$ and more than 67 subtypes (named a, b, c, etc.) (9). Sequence differences range from $31 \%$ to $33 \%$ among genotypes and from $20 \%$ to $25 \%$ among subtypes. Distribution of HCV genotypes is variable. Genotypes 1 to 3 have a worldwide prevalence, whereas genotypes 4 to 6 are more geographically restricted. Genotype 4 is found mainly in North Africa and the Middle East, especially in Egypt. Genotype 5 is restricted to South Africa and genotype 6 is found in South East Asia (10). The most dominant subtypes in south and north-west of Iran are 1a and 3a, respectively, while 1a predominates in all parts of Iran $(11,12)$.

Hepatitis C virus genotyping is important for the management of infected individuals and for epidemiology purposes (10). Genotypes indicate the route of acquisition, and affect the clinical outcome and response to treatment. For example response to interferon therapies in combination with ribavirin in patients infected with genotypes 1 and 4 is much lower than genotypes 2 and 3 . Infection with genotype 1 may proceed rapidly to severe chronic disease, cirrhosis, and hepatocellular carcinoma. Studies have shown that subtype $3 \mathrm{a}$ is significantly associated with transmission through IVDUs in industrial countries (4). Therefore, before any treatment, the genotype of the virus must be determined to estimate the dose, duration and type of antiviral drugs, and the virological monitoring method $(10,12)$.

\section{Objectives}

There are studies on the prevalence of HCV genotypes in infected individuals from Iran, yet they have not provided information about the overall distribution of HCV genotypes. Knowledge of the prevalence and distribution of HCV genotypes in infected individuals is important for successful treatment, control strategies and researches in the future. The aim of this study was to estimate the overall prevalence and trend of HCV genotypes in Iranian patients.

\section{Data Sources}

\subsection{Search Strategy and Selection Criteria}

The literature was searched to find scientific papers reporting the prevalence and distribution of HCV genotypes in Iran. Papers were identified through searching PubMed, Magiran, IranMedex, Scientific Information Databank (SID), and Google scholar databases. To search for as many related studies as possible, we used keywords including: "hepatitis C virus or HCV", "genotypes", "molecular epidemiology" and "Iran”. We also manually searched relevant Persian journals.

\section{Study Selection}

The inclusion criteria were:1) full text articles in English or Persian language reporting on HCV genotypes among infected patients with Iranian nationality; 2) studies using HCV RNA as a detection index of infected subjects that had data indicating the prevalence of HCV genotypes using standard genotyping methods. The exclusion criteria were: 1) studies with unknown sample origins; 2) studies with overlapping subjects, time and place of sample collection; 3) studies that failed to present data clearly; 4) any contraries to the inclusion criteria.

\section{Data Extraction}

All potentially relevant papers were reviewed independently by two investigators that assessed the eligibility of each article and the data were abstracted by the Excel data sheet. Irrelevant papers and papers that did not clearly report HCV genotypes were excluded. The following information were extracted from the papers: first author's name, study period (when the study was conducted), province or city of sampling, patients population, sample size, HCV genotypes and subtypes, genotype detection methods, gender, age, risk factors, etc.; although some papers did not contain all of these information.

For studies with duration of more than one year, the middle period of the time frame was used for analysis of trend. In addition, for some studies in which the prevalence of genotypes was reported annually, prevalence results of each year was considered in trend analysis. Our analysis was in accordance with the items of systematic reviews and meta-analyses (PRISMA) guidelines for systematic review.

\subsection{Statistical Analysis}

We considered studies reporting HCV genotypes (or subtypes) in Iran and 95\% confidence interval were calculated using random effects model and meta-analysis. The possibility of significant heterogeneity between studies was tested with the $\mathrm{Q}$ test $(\mathrm{P}<0.10$ indicated statistically significant heterogeneity) and the $\mathrm{I}^{2}$ statistic. FreemanTukey's double arcsine transformation was used to stabilize variances. In addition, Forest plot was performed for study locations and years. Data manipulation and statistical analyzes were done using the Meta R statistical software package, version 2.13. In meta-analyses with sufficient number of published papers, a funnel plot was inspected visually to assess for publication bias.

\section{Results}

\subsection{General Information of Samples}

A total of 73 original articles were found by the electronic search that reported HCV genotypes and subtypes from provinces and cities of Iran (Figure 1). After exclusion of ineligible papers, the final sample of the meta- 
analysis included 53 studies published between 1999 and 31 June 2014, including 44 studies in English, and 12 studies in Persian. Studies were done in 20 provinces or cities of Iran. In total, 22952 patients were meta-analyzed for pooled prevalence of HCV genotypes (Table 1).

The populations of studies were mainly chronic HCV infected patients including patients with hemophilia and thalassemia as well as those on hemodialysis, and multiply transfusion. In addition, a few studies included patients with a history of prison, dental visits, tattooing, unprotected sexual contact, kidney transplantation, intravenous drug use, and blood donation (Table 1). Since the genotypes and subtypes in the patients' populations were not reported separately, we were unable to analyze the prevalence of genotypes and subtypes according to population groups. Gender of patients was mostly male (45\% to 100\%) (Table 1). As genotypes according to patients' gender were not reported by all papers, we were unable to analyze the prevalence of genotypes according to gender. Due to data limitation, subtypes $2 \mathrm{a}$ and $2 \mathrm{~b}$ were not analyzed. Data regarding risk factors were not complete in published papers thus their analysis was not possible.

Different methods have been used for HCV genotyping in Iranian patients, including $5^{-}$-UTR restriction fragment length polymorphism (RFLP), DNA sequencing of NS5B or 5'-UTR/core genes, high resolution melting analysis, nucleic acid hybridization, and type-specific PCR for core region. Due to space restriction, we couldn't show data of genotyping methods for each paper in Table 1.

Table 1. Distribution of Hepatitis C Virus Genotypes and Subtypes in Patients From Cities and Provinces of Iran ${ }^{\text {a }}$

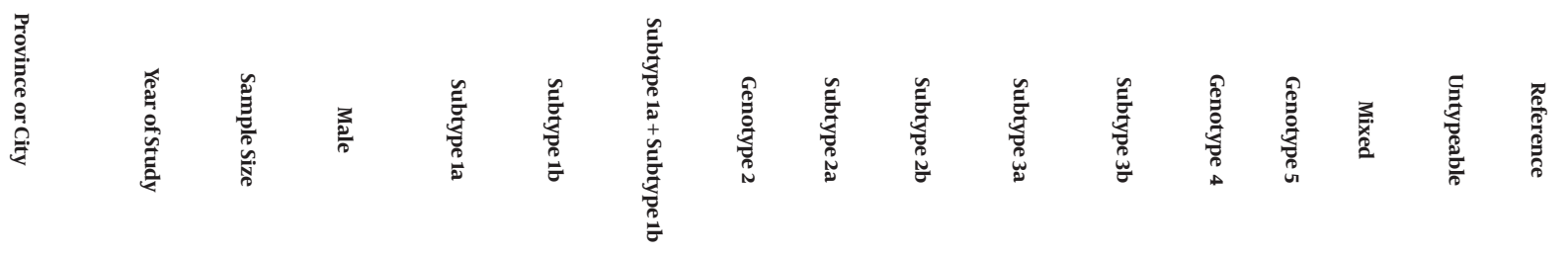

\begin{tabular}{|c|c|c|c|c|c|c|c|c|c|c|c|c|c|}
\hline \multicolumn{14}{|l|}{ Tehran } \\
\hline $\begin{array}{l}\text { Chronic } \\
\text { HCV } \\
\text { infected } \\
\text { patients }\end{array}$ & $\begin{array}{l}\text { March } \\
\text { 2003-De- } \\
\text { cember } \\
2011{ }^{b}\end{array}$ & 11561 & $9645(83.42)$ & $(44.90)$ & (11.3) & & $(0.70)$ & (39.6) & $(0.20)$ & $(0.80)$ & $\begin{array}{l}292 \\
(2.5)\end{array}$ & & (12) \\
\hline $\begin{array}{l}\text { Injection } \\
\text { drug users }\end{array}$ & $\begin{array}{l}\text { October } \\
\text { 2008-June } \\
2009\end{array}$ & 83 & $(97.80)$ & $35(42)$ & & & & $48(58)$ & & & & & (13) \\
\hline $\begin{array}{l}\text { Chronic } \\
\text { HCV } \\
\text { infected } \\
\text { thalassemic, } \\
\text { hemophilia } \\
\text { patients }\end{array}$ & $\begin{array}{c}\text { September } \\
\text { 2008-April } \\
2010\end{array}$ & 152 & $109(77.7)$ & $92(60.6)$ & $12(7.9)$ & & & $42(27.6)$ & & $2(1.3)$ & $4(2.6)$ & & (14) \\
\hline $\begin{array}{l}\text { Occult HCV } \\
\text { infected pa- } \\
\text { tients with } \\
\text { chronic } \\
\text { liver disease }\end{array}$ & $\begin{array}{l}\text { September } \\
\text { 2007-March } \\
2010\end{array}$ & 7 & $5(71)$ & $2(29)$ & $3(43)$ & & & $2(29)$ & & & & & (15) \\
\hline $\begin{array}{l}\text { HCV } \\
\text { infected } \\
\text { thalassemic, } \\
\text { hemophilia } \\
\text { patients }\end{array}$ & $\begin{array}{l}\text { September } \\
\text { 2008-April } \\
2009\end{array}$ & 133 & $100(75.2)$ & $85(63.9)$ & $8(6.0)$ & & & $35(26.2)$ & & $2(2.3)$ & $3(2.3)$ & & (16) \\
\hline $\begin{array}{l}\text { Blood } \\
\text { donors } \\
\text { and HCV } \\
\text { infected } \\
\text { patients }\end{array}$ & $\begin{array}{c}\text { December } \\
2006 \text { and } \\
\text { January } \\
2008\end{array}$ & 167 & ND & $87(52.1)$ & $14(29.3)$ & & & $55(12)$ & & & & $11(6.6)$ & (17) \\
\hline $\begin{array}{l}\text { Patients } \\
\text { with hemo- } \\
\text { philia }\end{array}$ & 2009 & 367 & $343(93.46)$ & (58) & $(14.70)$ & & $(0.80)$ & $(18.50)$ & & $(1.10)$ & $(6.20)$ & $(0.50)$ & (18) \\
\hline $\begin{array}{l}\text { Chronic } \\
\text { hepatitis C } \\
\text { patients }\end{array}$ & 2002-2005 & 384 & $307(79.9)$ & $154(40.1)$ & $43(11.2)$ & & & $105(27.3)$ & & & $3(0.8)$ & $76(19.8)$ & (19) \\
\hline $\begin{array}{l}\text { HCV } \\
\text { infected } \\
\text { patients }\end{array}$ & 2003-2005 & 2231 & $1853(83.1)$ & $886(39.7)$ & $271(12.1)$ & (1.3) & (1.4) & $613(27.5)$ & $(0.2)$ & (0.9) & $33(1.6)$ & $401(18)$ & (20) \\
\hline
\end{tabular}




\begin{tabular}{|c|c|c|c|c|c|c|c|c|c|c|c|c|c|c|c|}
\hline $\begin{array}{l}\text { Chronic } \\
\text { HCV } \\
\text { infected } \\
\text { IUDs }\end{array}$ & $\begin{array}{c}\text { December } \\
\text { 2008-March } \\
2009\end{array}$ & 36 & 35 & $(25)$ & $(16.70)$ & & & & $(58.3)$ & & & & & & (4) \\
\hline $\begin{array}{l}\text { HCV } \\
\text { infected } \\
\text { individuals }\end{array}$ & 1999 & 15 & ND & $7(47)$ & $3(20)$ & & & & $4(27)$ & & $1(6)$ & & & & (21) \\
\hline $\begin{array}{l}\text { Patients on } \\
\text { hemodi- } \\
\text { alysis }\end{array}$ & 2004 & 66 & $36(45.54)$ & $19(28.8)$ & $12(18.2)$ & $2(3)$ & & & $20(30.3)$ & $2(3)$ & $11(16.7)$ & & & & (22) \\
\hline $\begin{array}{l}\text { HCV } \\
\text { infected } \\
\text { patients }\end{array}$ & 2003-2004 & 214 & $141(65.88)$ & $117(52.88)$ & $\begin{array}{c}28 \\
(14.01)\end{array}$ & & & $1(2.1)$ & $63(27.57)$ & & $5(3.44)$ & & & & (23) \\
\hline $\begin{array}{l}\text { HCV } \\
\text { infected } \\
\text { patients }\end{array}$ & 2004 & 20 & ND & $11(55)^{c}$ & & & & & $4(20)$ & & & & & $5(25)$ & (24) \\
\hline \multicolumn{16}{|l|}{ Mashhad } \\
\hline $\begin{array}{l}\text { HCV-infect- } \\
\text { ed patients, } \\
\text { hemophilia }\end{array}$ & $\begin{array}{l}\text { October } \\
\text { 2009-Octo- } \\
\text { ber } 2010\end{array}$ & 382 & $299(79)$ & $147(39.2)$ & $41(10.9)$ & $4(1.04)$ & $9(2.4)$ & $9(2.4)$ & $150(40)$ & & & $13(3.4)$ & $3(0.8)$ & $4(2.5)$ & (25) \\
\hline $\begin{array}{l}\text { Hemo- } \\
\text { dialysis, } \\
\text { thalassemia, } \\
\text { injection, } \\
\text { blood } \\
\text { donors }\end{array}$ & 2003-2004 & 63 & ND & $19(30.10)^{C}$ & & & $10(15.9)$ & & $33(52.3)$ & & & & $1(1.6)$ & & (26) \\
\hline $\begin{array}{l}\text { Chronic } \\
\text { HCV infec- } \\
\text { tion }\end{array}$ & $2000-2010$ & 278 & $227(82)$ & $(36.30)$ & $(12.60)$ & & & $(0.40)$ & $(49.60)$ & & & & $(1.40)$ & & (11) \\
\hline \multicolumn{16}{|l|}{ Bushehr } \\
\hline $\begin{array}{l}\text { Blood } \\
\text { donors }\end{array}$ & 2007-2008 & 60 & $55(91.6)$ & $23(36.7)$ & $3(5)$ & $1(1.7)$ & & $2(3.3)$ & $22(38.3)$ & $1(1.7)$ & $1(1.7)$ & & $1(1.7)$ & $6(10)$ & (27) \\
\hline $\begin{array}{l}\text { HCV } \\
\text { infected } \\
\text { patients }\end{array}$ & 2007-2009 & 100 & $96(96)$ & $49(49)$ & $5(5)$ & & & & $40(40)$ & & & & $1(1)$ & $5(5)$ & (28) \\
\hline \multicolumn{16}{|l|}{$\begin{array}{l}\text { Tehran and } \\
\text { Rasht }\end{array}$} \\
\hline $\begin{array}{l}\text { HCV } \\
\text { infected } \\
\text { patients }\end{array}$ & 2009-2010 & 40 & ND & $19(42)$ & $7(20)$ & & & & $14(37.5 \%)$ & & & & & & (29) \\
\hline \multicolumn{16}{|l|}{ Guilan } \\
\hline $\begin{array}{l}\text { Chronic he- } \\
\text { modialysis } \\
\text { patients }\end{array}$ & $\begin{array}{l}\text { January- } \\
\text { May } 2008\end{array}$ & 32 & $24(75)$ & $19(59.4)$ & & & & & $13(40.6 \%)$ & & & & & & (30) \\
\hline \multicolumn{16}{|l|}{$\begin{array}{l}\text { Rasht } \\
\text { (Guilan) }\end{array}$} \\
\hline $\begin{array}{l}\text { Thalassemia } \\
\text { and chronic } \\
\text { HCV infec- } \\
\text { tion }\end{array}$ & $\begin{array}{c}\text { December } \\
\text { 1998-April } \\
2006\end{array}$ & 30 & $17(56.7)$ & $24(80)$ & & & & & $6(20)$ & & & & & & (31) \\
\hline \multicolumn{16}{|l|}{$\begin{array}{l}\text { Mazandaran } \\
\text { and Guilan }\end{array}$} \\
\hline $\begin{array}{l}\text { Patients } \\
\text { with thalas- } \\
\text { semia }\end{array}$ & $\begin{array}{c}\text { February } \\
\text { and March } \\
2010\end{array}$ & 28 & $15(53)$ & $9(32.1)$ & $1(3.6)$ & & & & $18(64.3)$ & & & & & & (32) \\
\hline \multicolumn{16}{|l|}{ Mazandaran } \\
\hline $\begin{array}{l}\text { Thalas- } \\
\text { semia, } \\
\text { hemophilia, } \\
\text { hemodialy- } \\
\text { sis, intrave- } \\
\text { nous drug } \\
\text { addicts }\end{array}$ & 2009-2011 & 135 & $94(69.6)$ & $37(27.40)$ & $11(8.20)$ & & & & $67(51.10)$ & & & & $16(11.9)$ & & (33) \\
\hline $\begin{array}{l}\text { Qaemshahr } \\
\text { (Mazanda- } \\
\text { ran) }\end{array}$ & & & & & & & & & & & & & & & \\
\hline
\end{tabular}


Khodabandehloo M et al.

\begin{tabular}{|c|c|c|c|c|c|c|c|c|c|c|c|c|c|}
\hline $\begin{array}{l}\text { DIAs, he- } \\
\text { modialysis, } \\
\text { transfusion, } \\
\text { surgery, } \\
\text { kidney } \\
\text { transplant }\end{array}$ & 2007-2010 & 86 & $74(86)$ & & & $36(41.8)^{d}$ & & $50(58.2)$ & & & & & (34) \\
\hline \multicolumn{14}{|l|}{$\begin{array}{l}\text { Sari and } \\
\text { Ghaemshahr }\end{array}$} \\
\hline $\begin{array}{l}\text { Hemodi- } \\
\text { alysis }\end{array}$ & 2009-2010 & 113 & $77(65.4)$ & & & $68(60.17)$ & & $44(38.93)$ & & $1(0.001)$ & & & (35) \\
\hline \multicolumn{14}{|l|}{ Ahvaz } \\
\hline $\begin{array}{l}\text { Patients } \\
\text { with hemo- } \\
\text { philia }\end{array}$ & $\begin{array}{l}\text { February } \\
\text { 2008-March } \\
2009\end{array}$ & 42 & $39(51.3)$ & $26(61.9)$ & $11(26.1)$ & & & $5(11.9)$ & & & & & (36) \\
\hline $\begin{array}{l}\text { Blood } \\
\text { donors }\end{array}$ & $2007-2008$ & 45 & $45(100)$ & $24(53.3)$ & & & & $17(37.7)$ & $4(8.8)$ & & & & (37) \\
\hline \multicolumn{14}{|l|}{$\begin{array}{l}\text { Khuzestan } \\
\text { province }\end{array}$} \\
\hline $\begin{array}{l}\text { Hemodialy- } \\
\text { sis patients }\end{array}$ & $\begin{array}{c}\text { March } \\
\text { 2005-Au- } \\
\text { gust 2006 }\end{array}$ & 17 & $9(47.36)$ & $7(41.1)$ & $4(23.5)$ & & & $6(35.2)$ & & & & & (38) \\
\hline $\begin{array}{l}\mathrm{HCV} \\
\text { infected } \\
\text { patients }\end{array}$ & 2005-2007 & 280 & $188(67.1)$ & $130(46.4)$ & $45(16.1)$ & $6(2.1)$ & & $99(35.4)$ & & & & & (38) \\
\hline \multicolumn{14}{|l|}{ Shahrekord } \\
\hline $\begin{array}{l}\text { HCV } \\
\text { infected } \\
\text { patients }\end{array}$ & 2009-2010 & 94 & $63(98.4)$ & $51(54.26)$ & $11(11.71)$ & & $2(2.12)$ & $26(27.66)$ & & $4(4.25)$ & & & (39) \\
\hline \multicolumn{14}{|l|}{ Shiraz } \\
\hline $\begin{array}{l}\text { Chronic } \\
\text { hepatitis: } \\
\text { drug } \\
\text { injection } \\
\text { abusers, } \\
\text { thalassemia, } \\
\text { hemodialy- } \\
\text { sis, sexual } \\
\text { contacts, } \\
\text { hemophili- } \\
\text { acs }\end{array}$ & 2010 & 634 & $550(86.8)$ & $137(26.2)$ & $55(8.7)$ & $4(0.6)$ & $15(2.4)$ & $259(40.9)$ & & & $8(1.3)$ & $156(24.6)$ & (40) \\
\hline $\begin{array}{l}\text { Thalas- } \\
\text { semia, histo- } \\
\text { ry of prison, } \\
\text { dental visits, } \\
\text { hemophilia, } \\
\text { hemodi- } \\
\text { alysis and } \\
\text { tattooing }\end{array}$ & 2004-2005 & 238 & $152(64)$ & $103(43.3)$ & $39(16.4)$ & & & $96(40.3)$ & & & & & (41) \\
\hline $\begin{array}{l}\text { Patients } \\
\text { with } \\
\text { chronic } \\
\text { hepatitis }\end{array}$ & 2003-2006 & 118 & & $26(22)$ & $11(9.3)$ & & & $48(40.7)$ & & & & $14(11.9)$ & (42) \\
\hline \multicolumn{14}{|l|}{ Zahedan } \\
\hline $\begin{array}{l}\text { HCV } \\
\text { infected } \\
\text { Patients }\end{array}$ & $\begin{array}{l}\text { July } \\
\text { 2007-April } \\
2009\end{array}$ & 52 & $39(75)$ & $28(53.84)^{C}$ & & & $2(3.88)$ & $12(23.08)$ & & $7(13.4)$ & $3(5.77)$ & & (43) \\
\hline $\begin{array}{l}\text { Thalassemia } \\
\text { and chronic } \\
\text { HCV infec- } \\
\text { tion }\end{array}$ & $\begin{array}{c}\text { August } \\
\text { 2005-Sep- } \\
\text { tember } \\
2007\end{array}$ & 20 & $13(65)$ & $3(15)$ & $5(25)$ & & & $8(40)$ & & & & $4(20)$ & (44) \\
\hline \multicolumn{14}{|l|}{$\begin{array}{l}\text { Yazd Prov- } \\
\text { ince }\end{array}$} \\
\hline $\begin{array}{l}\text { IV drug } \\
\text { addicts }\end{array}$ & $\begin{array}{l}2007 \text { and } \\
2010\end{array}$ & 71 & $68(95.7)$ & $25(35)$ & & & & $46(65)$ & & & & & (45) \\
\hline $\begin{array}{l}\text { HCV } \\
\text { infected } \\
\text { patients }\end{array}$ & $\begin{array}{l}\text { March 2010- } \\
\text { June } 2013\end{array}$ & 191 & 152 (79.6) & $74(38.7)$ & $13(6.8)$ & & $3(1.6)$ & $96(50.3)$ & & & $(2.60)$ & & (2) \\
\hline
\end{tabular}


Khodabandehloo M et al.

\begin{tabular}{|c|c|c|c|c|c|c|c|c|c|c|c|c|c|c|c|}
\hline \multicolumn{16}{|l|}{$\begin{array}{l}\text { Isfahan } \\
\text { Province }\end{array}$} \\
\hline $\begin{array}{l}\mathrm{HCV} \\
\text { infected } \\
\text { Patients }\end{array}$ & $\begin{array}{l}\text { March } 2007 \\
\text { and April } \\
2009\end{array}$ & 97 & $95(97.70)$ & (29.50) & (5.10) & & $(2.00)$ & & & $(61.20)$ & & & (2) & & (46) \\
\hline \multicolumn{16}{|l|}{ Golestan } \\
\hline $\begin{array}{l}\text { Blood } \\
\text { donors }\end{array}$ & 2009-2010 & 91 & $70(90.90)$ & $15(16.48)$ & $15(16.48)$ & $1(1.01)$ & & $2(2.19)$ & & $12(13.18)$ & $19(20.87)$ & $6(6.59)$ & $7(7.69)$ & $14(15.38)$ & (47) \\
\hline \multicolumn{16}{|l|}{ Iran } \\
\hline $\begin{array}{l}\text { General } \\
\text { population } \\
\text { patients }\end{array}$ & $\begin{array}{c}2004 \\
\text {-December } \\
2007\end{array}$ & 206 & $83(172)$ & $53(25.73)$ & $\begin{array}{c}36 \\
(17.47)\end{array}$ & & $4(1.95)$ & & & $96(46.6)$ & & & $11(5.33)$ & $6(2.91)$ & (48) \\
\hline \multicolumn{16}{|l|}{$\operatorname{Iran}^{\mathrm{e}}$} \\
\hline $\begin{array}{l}\text { HCV } \\
\text { infected } \\
\text { patients }\end{array}$ & $\begin{array}{l}\text { June 2002- } \\
\text { May } 2003\end{array}$ & 156 & 125 & $59(37.8)$ & $26(16.7)$ & $2(1.28)$ & & & & $45(28.8)$ & & $2(1.28)$ & 1 & $21(13.46)$ & (49) \\
\hline \multicolumn{16}{|l|}{$\begin{array}{l}\text { Different } \\
\text { parts of } \\
\text { Iran }\end{array}$} \\
\hline $\begin{array}{l}\text { HCV posi- } \\
\text { tive carriers }\end{array}$ & 2000-2005 & 116 & $93(80.17)$ & $(61.20)$ & $(13.80)$ & & & & & (25) & & & & & (50) \\
\hline \multicolumn{16}{|l|}{$\begin{array}{l}\text { Tehran, Ta- } \\
\text { briz, Guilan } \\
\text { and Shiraz }\end{array}$} \\
\hline $\begin{array}{l}\text { Multiply } \\
\text { transfused } \\
\text { patients } \\
\text { with thalas- } \\
\text { semia and } \\
\text { chronic } \\
\text { hepatitis C }\end{array}$ & 2008 & 280 & $165(59)$ & $146(52)$ & $14(5)$ & $3(1.1)$ & & $3(1.1)$ & & $97(34.5)$ & $1(0.4)$ & & $16(3.4)$ & $7(2.5)$ & (51) \\
\hline \multicolumn{16}{|l|}{$\begin{array}{l}\text { East Azerbai- } \\
\text { jan }\end{array}$} \\
\hline $\begin{array}{l}\text { HCV } \\
\text { infected } \\
\text { patients on } \\
\text { dialysis }\end{array}$ & 2006 & 55 & $49(92.45)$ & $42(76.4)$ & $3(5.5)$ & $1(1.8)$ & & & & $3(5.5 \%)$ & & & & $4(10.9 \%)$ & (52) \\
\hline \multicolumn{16}{|l|}{$\begin{array}{l}\text { West Azer- } \\
\text { baijan }\end{array}$} \\
\hline $\begin{array}{l}\mathrm{HCV} \\
\text { infected } \\
\text { patients }\end{array}$ & 2006-2008 & 160 & & & & $13(8.12)^{d}$ & & $19(11.87)$ & $35(21.87)$ & $77(48.12)$ & & $16(10.0)$ & & & (53) \\
\hline \multicolumn{16}{|l|}{$\begin{array}{l}\text { Tehran, } \\
\text { Kerman, Ker- } \\
\text { manshah }\end{array}$} \\
\hline $\begin{array}{l}\text { HCV in- } \\
\text { fected blood } \\
\text { donors }\end{array}$ & $\begin{array}{c}\text { December } \\
2006 \text { and } \\
\text { January } \\
2008\end{array}$ & 103 & $101(98.1)$ & $53(51.5)$ & $4(3.9)$ & & & & & $39(37.9)$ & & & & $7(6.8)$ & (54) \\
\hline \multicolumn{16}{|l|}{$\begin{array}{l}\text { Tehran, Sari, } \\
\text { Tabriz, Oro- } \\
\text { mieh, Ker- } \\
\text { manshah, } \\
\text { Zahedang }^{\text {Zahedal }}\end{array}$} \\
\hline $\begin{array}{l}\text { HCV } \\
\text { infected } \\
\text { patients }\end{array}$ & 1999-2003 & 125 & ND & $59(47)$ & $10(8)$ & & & & $1(0.8)$ & $45(36)$ & & $9(7)$ & & & (55) \\
\hline \multicolumn{16}{|l|}{$\begin{array}{l}\text { Markazi } \\
\text { Province }\end{array}$} \\
\hline $\begin{array}{l}\text { Patients on } \\
\text { hemodi- } \\
\text { alysis }\end{array}$ & $\begin{array}{c}\text { March-July } \\
2005\end{array}$ & 8 & $1(12.5)$ & $4(50)$ & $1(12.5)$ & & & & & $1(12.5)$ & & $2(25)$ & & & (56) \\
\hline \multicolumn{16}{|l|}{ Markazi } \\
\hline $\begin{array}{l}\text { Thalas- } \\
\text { semia and } \\
\text { inherited } \\
\text { bleeding } \\
\text { disorders }\end{array}$ & $\begin{array}{c}\text { March-July } \\
2004\end{array}$ & 23 & $31(93.9)$ & $9(40.9)$ & $2(9.1)$ & & $1(4.54)$ & & & $4(18.2)$ & & & $6(27)$ & & (57) \\
\hline
\end{tabular}




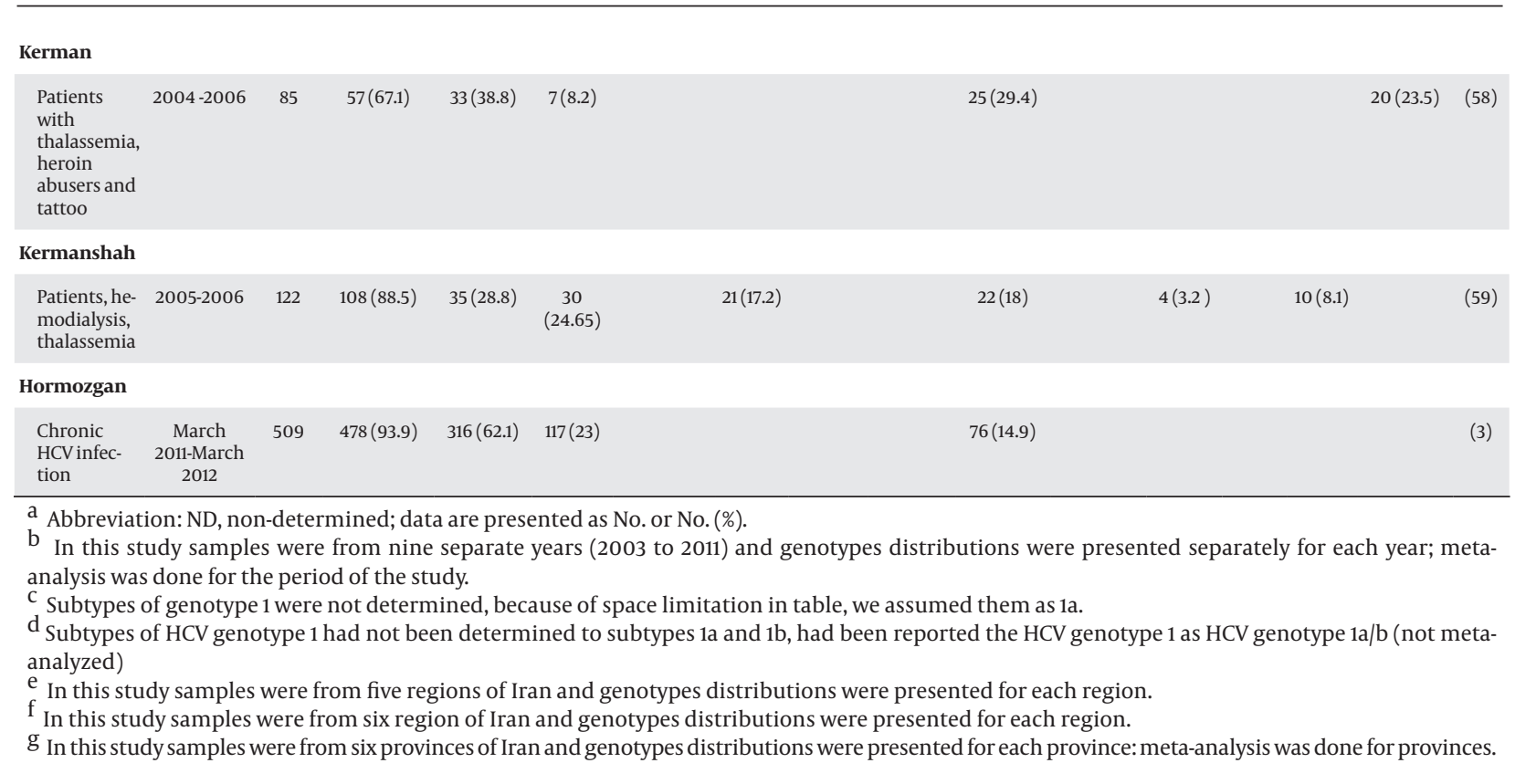

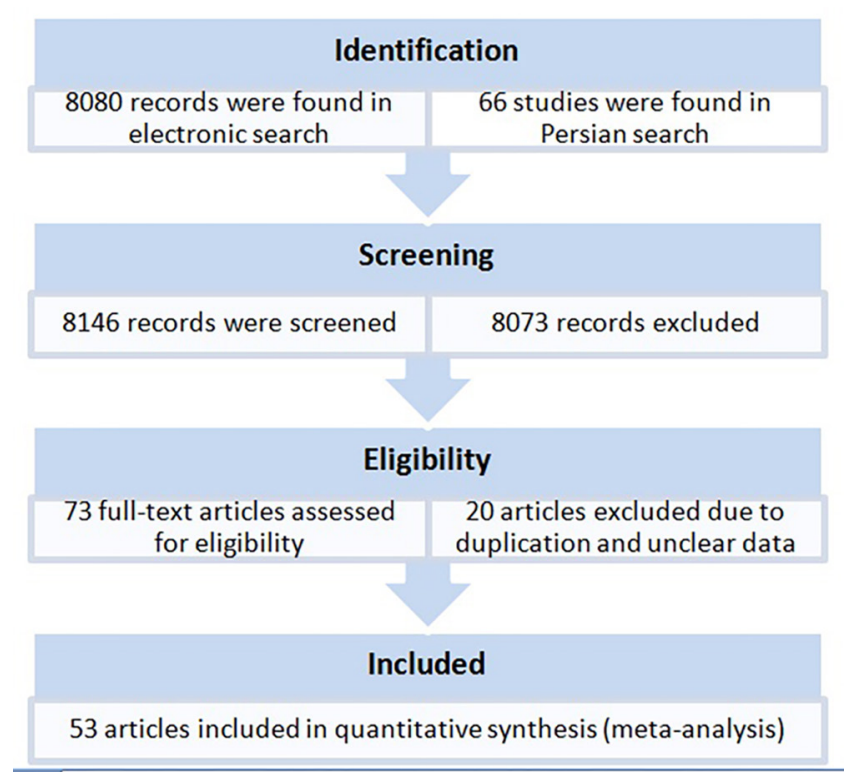

Figure 1. Flow Chart of Literature Search for Original Articles in English and Persian Reporting HCV Genotypes and Subtypes From Provinces and Cities of Iran

\subsection{Prevalence of HCV Genotypes and Subtypes in Iran Provinces and Cities}

All studies were divided into 20 groups according to the place of sampling. Some studies were reporting HCV genotypes from all of Iran without separating data according cities or provinces; we included them in a separate group named, Iran (Table 1, Figure 2). Estimated pooled prevalence of HCV genotypes in patients distributed in provinces and cities of Iran were as follows; Subtype 1a was the predominant genotype with a rate of 39\% (34-44\%, 95\% CI); followed by subtype 3a, 32\% (26-39\%, 95\% CI); subtype $1 \mathrm{~b}$, 13\% (10-15\%, 95\% CI); genotype 4, 5.18\% (3.27-7.5\%, 95\% CI); and genotype 2 , 3.6\% (1.6-8.3\%, 95\% CI), respectively. Untypeable HCV was $0.3 \%$ (95\% CI: 0.07-0.16\%). Remnants were mixed genotypes $1.96 \%$, genotype $5,0.056 \%$ and other subtypes (Table 1, Figure 1). Genotype 6 was reported only in one study with prevalence rate $1(0.7 \%)$ with subtype $6 a(60)$.

Estimated overall prevalence of HCV genotypes was variable in cities and provinces of Iran. For example, subtype 


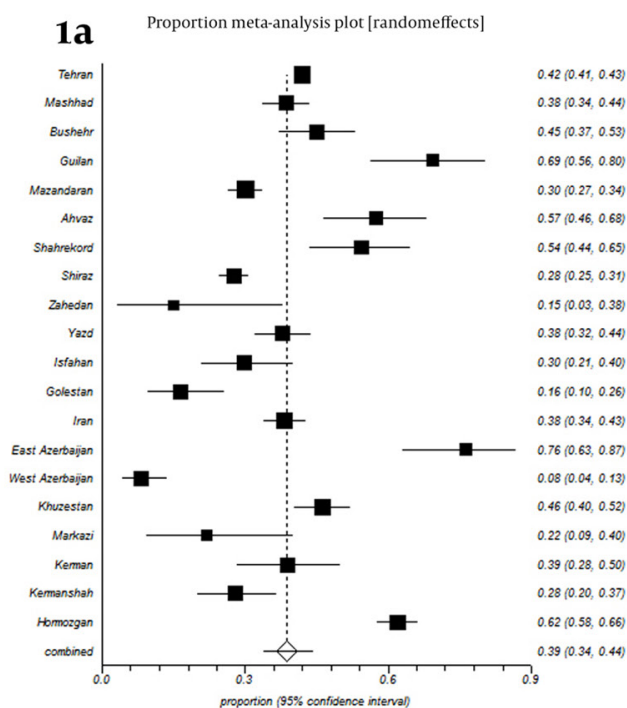

2 Proportion meta-analysis plot [randomeffects

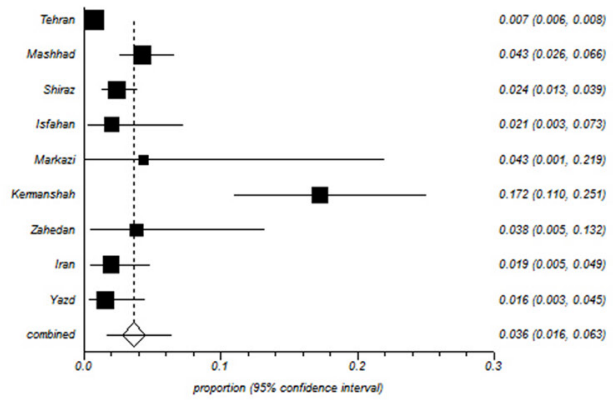

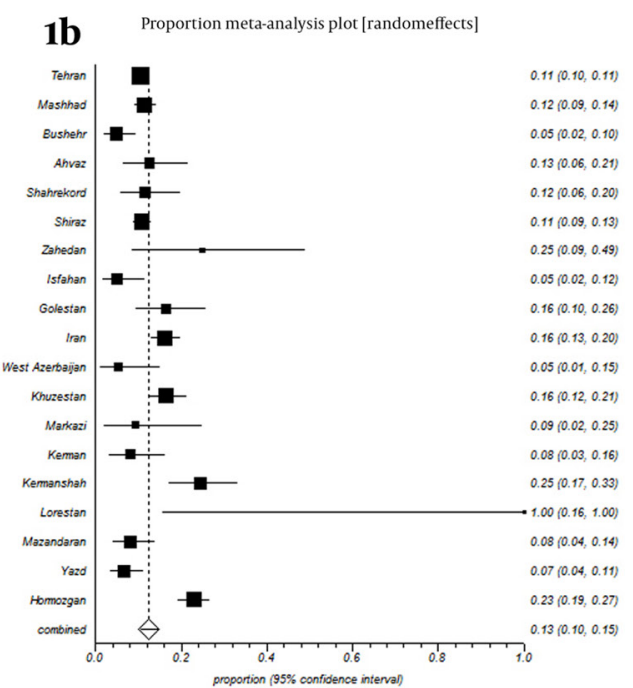

4 Proportion meta-analysis plot [randomeffects]

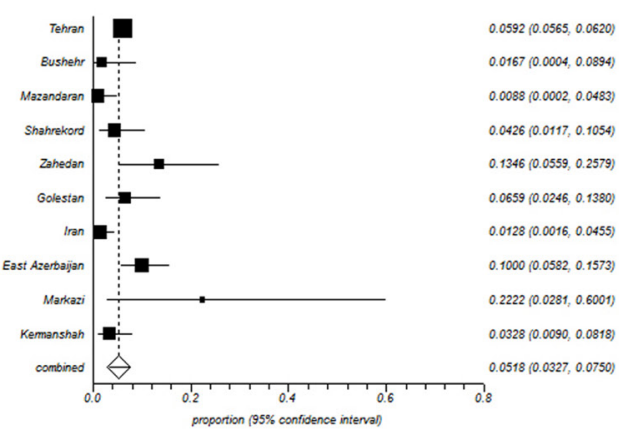

$3 a$ Proportion meta-analysis plot [randomeffects]

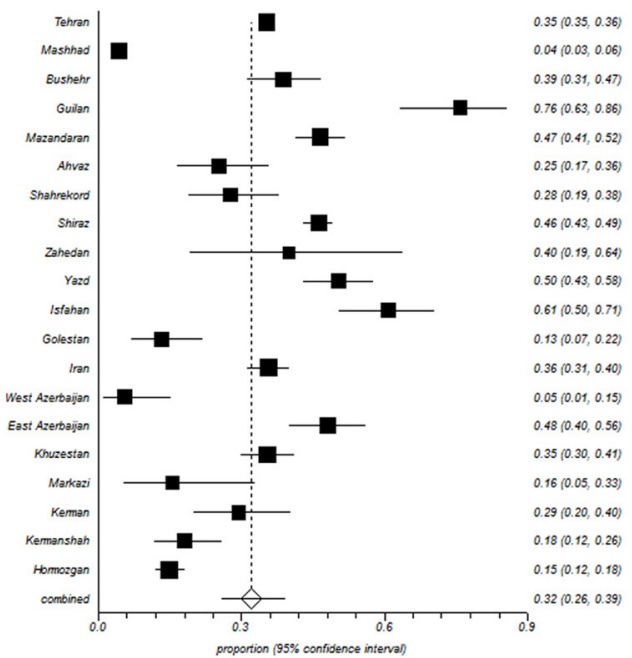

Figure 2. Forest Plot Showing Hepatitis C Virus Genotypes and Subtypes 1a, 1b, 2, 3a and 4 Prevalence Estimates in Patients of Iranian Cities and Provinces 
$1 a$

Proportion meta-analysis plot [randomeffects]

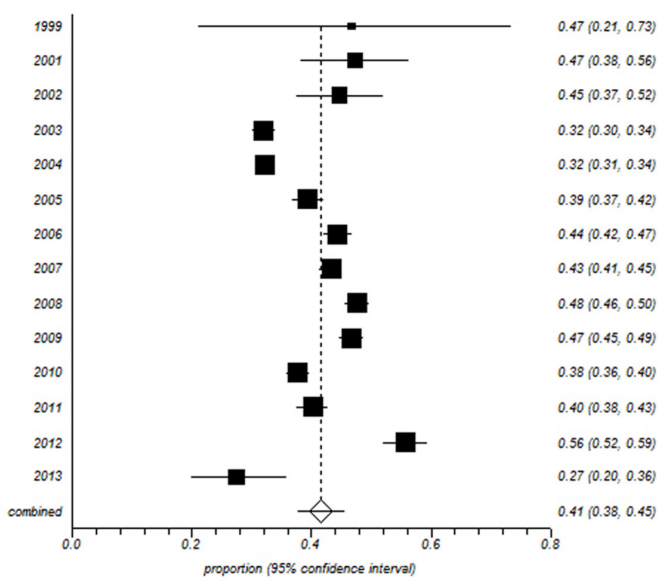

2

Proportion meta-analysis plot [randomeffects]

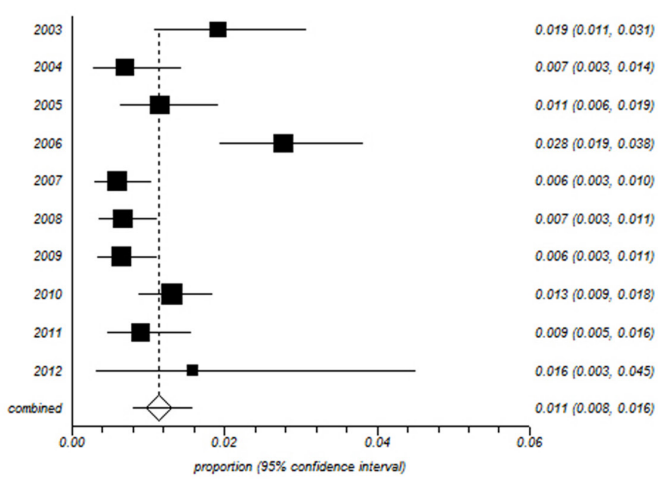

1 Proportion meta-analysis plot [randomeffects]

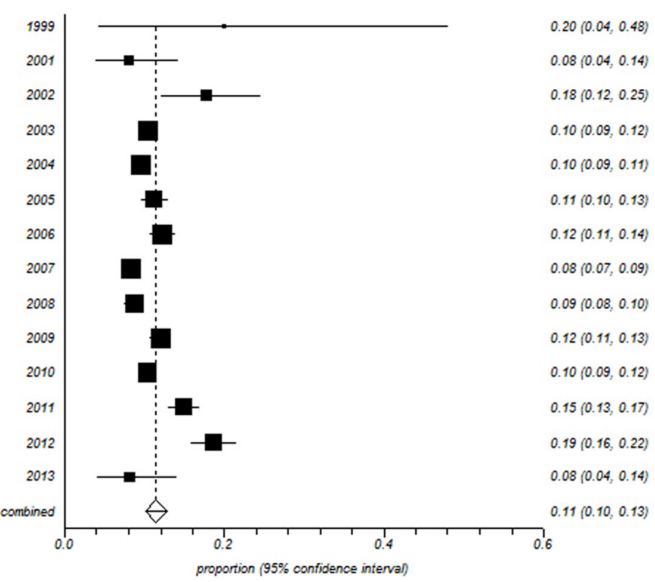

$4 \quad$ Proportion meta-analysis plot [randomeffects]

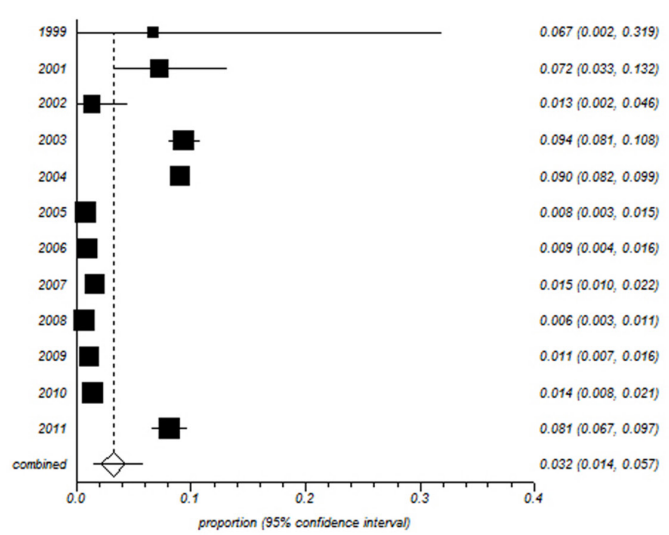

3a Proportion meta-analysis plot [randomeffects]

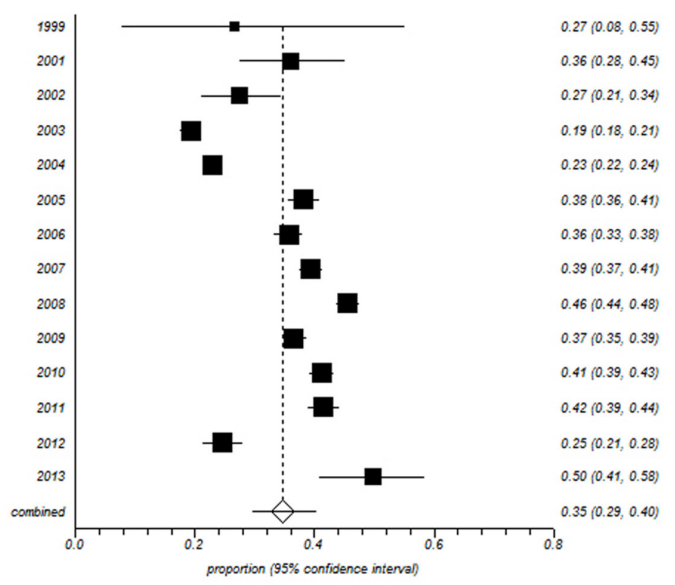

Figure 3. Forest Plot Showing Hepatitis C Virus Genotypes and Subtypes 1a, 1b, 2, 3a and 4, Prevalence Estimates in Iranian Patients According to Study Period 


\section{$1 a$}

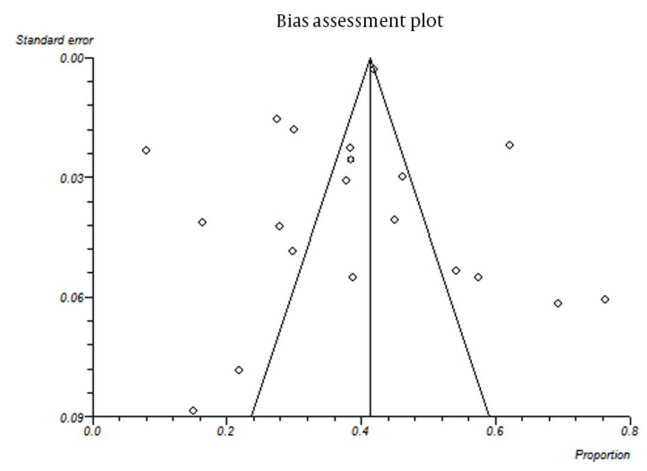

2

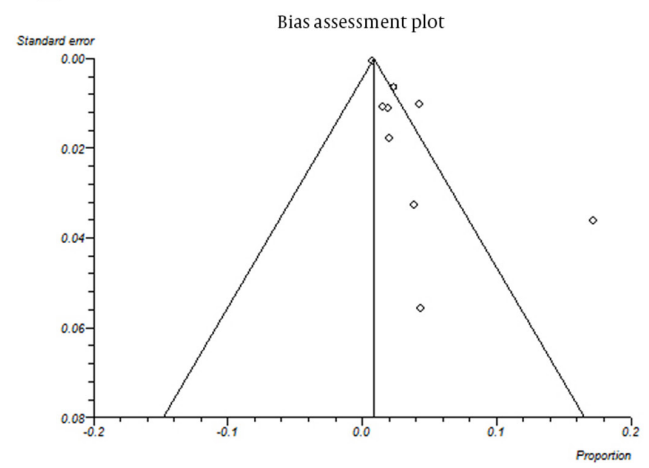

$\mathbf{1 b}$
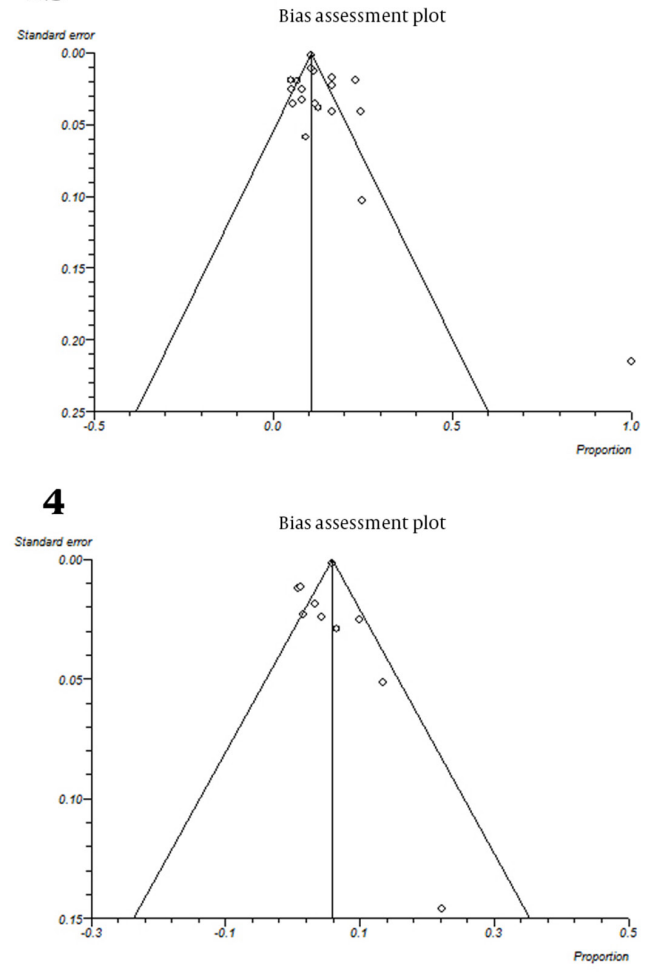

$3 a$

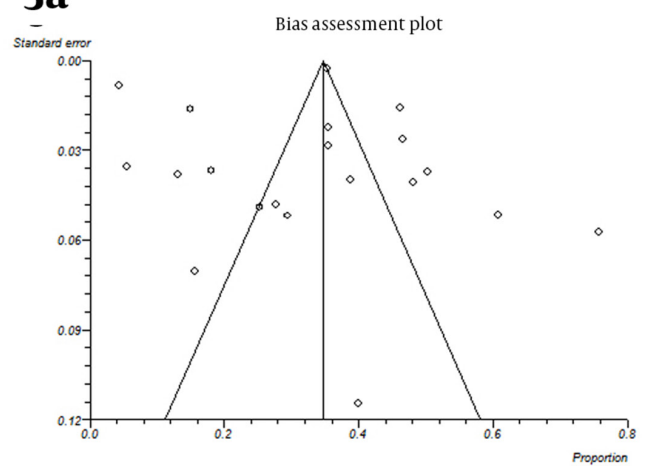

Figure 4. Funnel Plot Detecting Biases in the Identification and Selection of Studies for HCV Genotypes and Subtypes 1a, 1b, 2, 3a, and 4 in Iranian Cities and Provinces

1a was maximum in East Azarbyjan, 76\% (95\% CI: 63-87\%) and Guilan, 69\% (95\% CI: 56-80\%) respectively; but minimum in West Azarbayjan, 8\% (95\% CI: 4-13\%). Prevalence of subtype 3a was variable in cities and provinces of Iran, for instance, maximum in Guilan, 76\% (95\% CI 63-86\%) and Isfahan, 61\% (95\% CI, 50-71\%) yet, minimum in West Azarbyjan, 5\% (95\% CI, 1-15\%). Prevalence of subtype 1b was 13\% (95\% CI:10-15\%) in Iran, while in Kermanshah, Zahedan and Hormozgan, it was 25\% (95\% CI: 17-33\%), 25\% (95\% CI: 9-49\%), and 23\% (95\% CI: 19-27\%) respectively. Prevalence of genotype 2 was $0.7 \%$ (95\% CI: 0.06-0.8\%) in Tehran, while in Kermanshah it was 17.2\% (95\% CI: 11-25.1\%) (Figure 2).

\subsection{Time}

All studies were divided into 14 groups according to the year of study. The estimated annual prevalence rates of HCV genotypes over years are shown in Figure 3. Funnel plots for detecting biases in published papers are presented in Figures 4 and 5.

\section{Conclusions}

The frequency of HCV genotypes in different geographic regions is variable and changes over time, depending on the study population, the route of infection and virus 
$1 a$

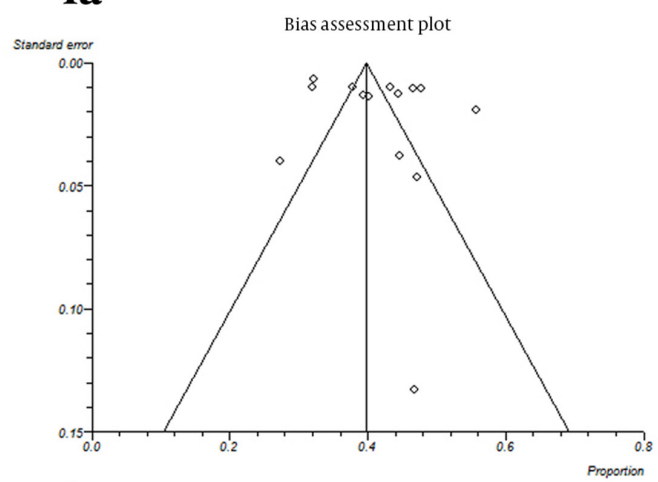

2

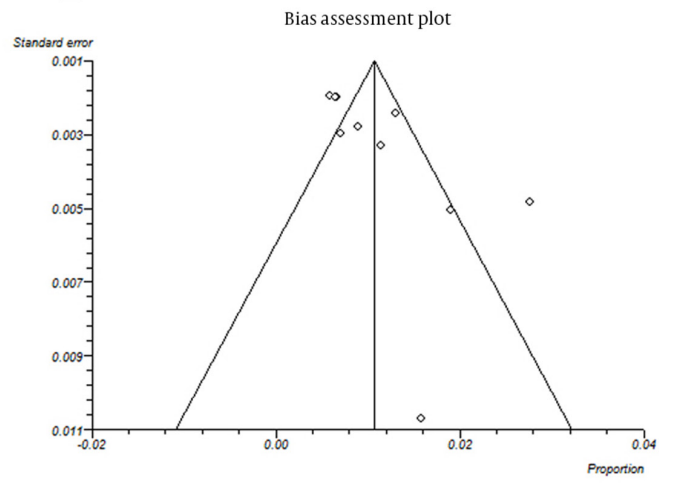

$\mathbf{1 b}$

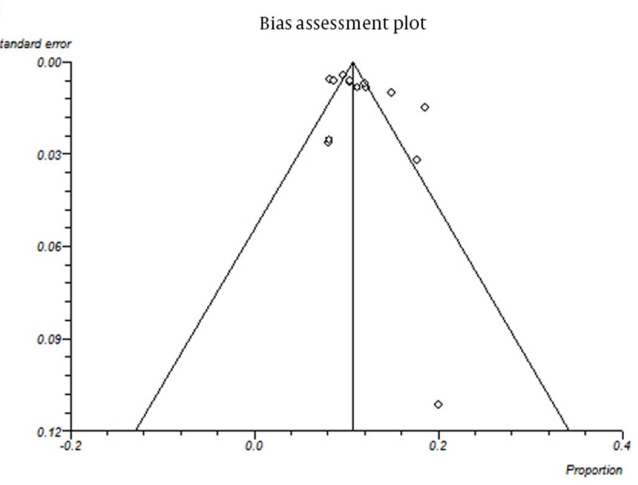

4

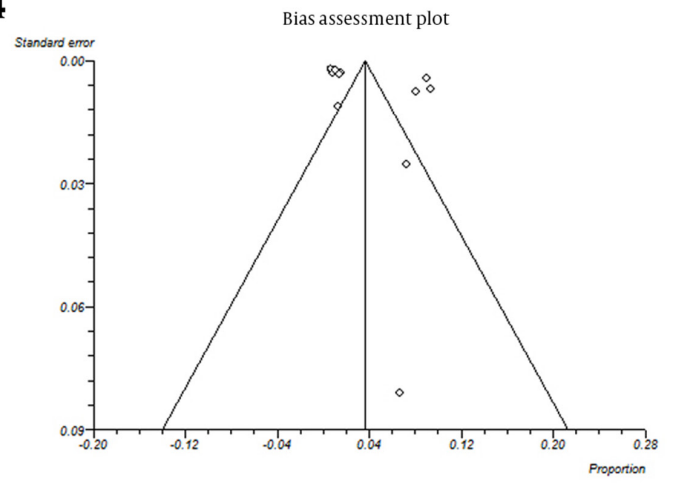

$3 a$

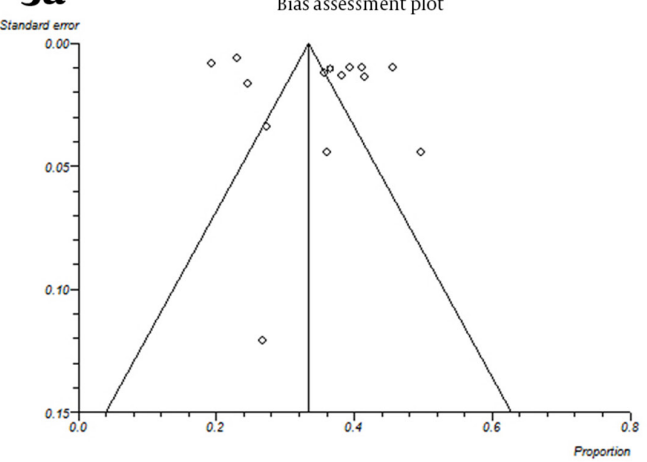

Figure 5. Funnel Plot Detecting Biases in the Identification and Selection of Studies for HCV Genotypes and Subtypes 1a, 1b, 2, 3a, and 4 According to Study Periods

mutation $(3,11)$. Considering countries around Iran, the predominant HCV subtype is $1 \mathrm{~b}$ in Turkey, Russia, Moldova and Uzbekistan (10), 4 in Saudi Arabia, Iraq, Qatar, Bahrain, Kuwait and Yemen (12), and 6a in China (3). The predominant subtype is 3a in Pakistan (6) and India (33). Despite the high number of visitors from and to Arab countries (Iraq, Qatar, Bahrain, Saudi Arabia, Kuwait) with predominant genotype 4, and visitors from north neighboring countries such as Tajikistan and Turkmenistan with the predominant subtype $1 \mathrm{~b}$; subtype 1a is dominant in Iran. It is probable that differences in the population, routes of transmission, and socioeconomic factors may explain this variation.
The prevalence of genotype 4 in Iran is lower compared to the majority of Middle Eastern countries including the neighboring Arabic countries. In Iran genotype 4 is prevalent in patients on hemodialysis and this is related to communication with neighboring countries such as Iraq and Saudi Arabia during the pilgrims and Hajj ceremony. There are no reliable reports about HCV genotypes in Afghanistan, the eastern neighbor of Iran. During the past few years, due to the political situation of Afghanistan, a considerable number of immigrants came to Iran. These immigrants usually do many trips between Iran, Afghanistan and Pakistan (11).

Only one study has reported HCV genotype 5 (3.4\%) in 
their study population (25), which can be a result of genotyping mistake and should be confirmed by DNA sequencing. Genotype 6 was reported only in one study with a prevalence rate of $1 / 142(0.7 \%)$ with subtype $6 a$ in one patient who had referred to the Gastroenterology Department of Taleghani Hospital (Tehran, Iran) between June 2007 and June 2012 (60). It seems that this patient was infected by HCV in a country other than Iran. In one study that was performed recently on 11561 chronic HCV infected patients in Iran, the results revealed that, 1a was common (44.9\%) followed by $3 a$ (39.6\%) and $1 \mathrm{~b}(11.3 \%)$ (12). Distribution of HCV genotypes in our population is similar to the pattern on HCV in northern Europe, where genotypes 1,2 and 3 are more frequent $(25,33)$.

In the last decade, an increase in HCV genotype distribution has been reported in many countries, for example there has been an increase in the prevalence of the $3 a, 1 a$, and 4 (12). Documents have indicated that HCV infection has risen dramatically in the recent years in the Middle East region. This might be related to changes in the main route of transmission (61). Subtype $1 \mathrm{a}$ and $1 \mathrm{~b}$ are the dominant genotypes in older and $3 a$ in young patients in Iran (25). The high prevalence of subtype 3a in young patients suggests an increased number of IVDU as the main route of HCV transmission. In addition, recent studies have indicated that there is an increase in the frequency of $3 a$ in the younger population of Iran, Germany, Serbia, Montenegro, and Slovenia; this is because the main route for transmission of HCV is IVDU, due to sharing of unsterilized needles and syringes. Therefore, young male individuals are more susceptible to acquire HCV infection (12).

Considering forest plots in Figure 3, our results showed that trend of hepatitis $C$ virus genotypes $1 \mathrm{a}$ and $1 \mathrm{~b}$ was fluctuating from 1999 to 2013, with a sinus shape, reaching maximum levels in 2012 and minimum levels in 2013; the reasons of these fluctuations are unknown. The overall trend of genotypes 2 and 4 was decreasing yet there was an increase for genotype 2 in 2012 and genotype 4 in 2011. The overall trend of subtype 3a decreased from 2001 to 2003 yet increased from 2004 to 2011, while it suddenly decreased in 2012 followed by a sharp increase to maximum levels in 2013. The reasons of these fluctuations is unknown. It must be noted that changes in the route of transmission and easy travelling in the recent years are the probable cause. Further researches are needed to find definitive answers.

Mixed HCV infection with more than one genotype is possible. Numerous reports suggest that HCV infection with one genotype does not prevent becoming infected with other HCV genotypes. Multiple exposures to HCV may occur from time to time. Mixed infections may lead to severe disease, poor response to antiviral therapy or relapse after treatment. Studies have reported that mixed infection with two genotypes of HCV occurs in approximately $1 \%$ of HCV infected patients, and 1.6 to $31 \%$ of patients with multi-transfused hemophilia. In one study multiple HCV subtypes (1a and 3a) were detected in 2.5\% of the patients (12). In the present study the prevalence of mixed HCV infection was $1.96 \%$, which is compatible with previous reports.

A funnel plot is helpful for detecting biases around the line of identity in the meta-analysis. In our study the bias assessment plot was symmetric for subtypes $1 \mathrm{a}, 1 \mathrm{~b}, 3 \mathrm{a}$ and genotype 4 , yet asymmetric for genotype 2 in papers reporting HCV genotypes in Iranian cities (Figure 4). Research insufficiency may be the reason of bias for genotype 2 . Also, according to study periods, bias assessment plots were symmetric for genotypes or subtypes $1 \mathrm{a}, 1 \mathrm{~b}, 2$, 4 and $3 a$ (Figure 5).

Forest plots of the present study indicated heterogeneity in the published papers (Figures 2 and 3). On the other hand, forest plots showed that, as the sample size increases confidence intervals of estimated prevalence become narrower. Thus, large sample sizes increase the precision of the study. In addition, samples collected from some parts of Iran were not adequate for obtaining firm conclusions.

A proportion of HCV in Iranian patients was reported untypeable. Presence of untypeable HCV samples in some studies indicates the inability of genotyping methods to discriminate HCV genotypes. To be able to identify untypeable HCV genotypes, sequencing and phylogenetic analysis of viral genome is needed for characterization. Thus, the future goal of researches should be to sequence genomes of untypeable samples. However, in some papers of the present study genotypes of HCV were detected by sequencing.

The transmission of HCV occurs mainly through infected blood, blood products, and contaminated devices, such as syringes and needles. Today, intravenous drug use is an important route of HCV transmission $(4,61)$. Precise data about the pattern of HCV genotypes and continuous monitoring of the genetic diversity of virus isolates, especially among high-risk individuals (hemophilia, thalassemia, hemodialysis, multiply transfused patients and intravenous drug use) is essential for understanding HCV epidemiology (33). The evaluation of HCV risk factors among patient populations is important. Most studies did not report on HCV genotypes in patient populations completely. Because of this defect in data, we were unable analyze the prevalence of HCV genotypes according to patient's population.

Male gender was reported as an independent predictive factor for HCV infection in previous studies (61). The findings of a recent study showed that there was no association between having a variety of HCV genotypes and gender, level of education, risk factors, job, income, HIV infection, HBV infection, IV drug abuse and presence of underlying diseases (3). In our study most of the HCV infected patients were male (Table 1 ). However, most studies have not reported prevalence of HCV genotypes according to gender and above-mentioned factors separately. Thus, we were unable analyze the prevalence of HCV genotypes according to gender and risk factors. 
A range of studies on the prevalence of HCV genotypes in Iranian patients have been conducted. A meta-analysis of these prevalence data would be important for public health policy making and planning of clinical services addressing the needs of these infected people. The advantage of this meta-analysis is that it merges a large sample size and long study period, which help draw a reliable estimate of HCV genotypes distribution in Iran. Our study had a number of limitations that should be mentioned. First, different HCV genotyping methods were used by various studies and this may impact the obtained results of this meta-analysis. Second, although study populations were all Iranian patients, yet some populations were special patient groups and including them in a meta-analysis is somewhat challenging. Furthermore, data limitations of some studies did not allow their analysis.

In conclusion, our study showed that the most frequent subtypes of HCV in Iran were $1 \mathrm{a}, 3 \mathrm{a}$ and $1 \mathrm{~b}$, respectively. This frequency differs in cities and provinces of Iran and neighboring countries. Also, this meta-analysis reported on the overall estimate for distribution of HCV genotypes in Iran. Therefore, due to the possibility of changing dominant viral genotypes in communities based on migrations and viral genome mutations, it is important to determine distribution of HCV genotypes in different geographical areas and its trend with time for epidemiological and patient management purposes.

\section{Acknowledgements}

We would like to thank the Kurdistan University of Medical Sciences for their supports.

\section{Funding/Support}

The submitted manuscript was a meta-analysis and the Kurdistan University of Medical Sciences funded the project.

\section{References}

1. Mohd Hanafiah K, Groeger J, Flaxman AD, Wiersma ST. Global epidemiology of hepatitis $C$ virus infection: new estimates of age-specific antibody to HCV seroprevalence. Hepatology. 2013;57(4):1333-42.

2. Hadinedoushan H, Salmanroghani H, Amirbaigy MK, AkhondiMeybodi M. Hepatitis C virus genotypes and association with viral load in yazd, central province of iran. Hepat Mon. 2014;14(3).

3. Mousavi SF, Moosavy SH, Alavian SM, Eghbali H, Mahboobi H. Distribution of hepatitis $\mathrm{C}$ virus genotypes among patients with hepatitis $\mathrm{C}$ virus infection in hormozgan, iran. Hepat Mon. 2013;13(12).

4. Ranjbar Kermani F, Sharifi Z, Ferdowsian F, Paz Z, Zamanian M Distribution of Hepatitis C Virus Genotypes Among Chronic Infected Injecting Drug Users in Tehran, Iran. Jundishapur J Microbiol. 2013;6(3):265-8.

5. Khodabandehloo M, Roshani D, Sayehmiri K. Prevalence and trend of hepatitis $\mathrm{C}$ virus infection among blood donors in Iran: A systematic review and meta-analysis. $J$ Res Med Sci. 2013;18(8):674-82.

6. Attaullah S, Khan S, Ali I. Hepatitis C virus genotypes in Pakistan: a systemic review. Virol J. 2011;8:433.
7. Fallahian F, Najafi A. Epidemiology of hepatitis $C$ in the Middle East. Saudi J Kidney Dis Transpl. 2011;22(1):1-9.

8. Ray Stuart C, Bailey JR, Thomas DL. Hepatitis C Virus. In: Knipe DM, Howley PM editors. Field's Virology. 6 ed. Philadelphia: Wolters Kluwer Lippincott Williams \& Wilkins;2014. pp. 795-824.

9. Smith DB, Bukh J, Kuiken C, Muerhoff AS, Rice CM, Stapleton JT, et al. Expanded classification of hepatitis $C$ virus into 7 genotypes and 67 subtypes: updated criteria and genotype assignment web resource. Hepatology. 2014;59(1):318-27.

10. Bokharaei-Salim F, Keyvani H, Monavari SH, Alavian SM, Fakhim S, Nasseri S. Distribution of hepatitis $C$ virus genotypes among azerbaijani patients in capital city of iran-tehran. Hepat Mon. 2013;13(9).

11. Rastin M, Mahmoudi M, Rezaee SA, Assarehzadegan MA, Tabasi $\mathrm{N}$, Zamani S, et al. Distribution of Hepatitis $\mathrm{C}$ virus genotypes in city of Mashhad, North-east of Iran. Indian J Med Microbiol. 2014;32(1):53-6.

12. Jahanbakhsh Sefidi F, Keyvani H, Monavari SH, Alavian SM, Fakhim S, Bokharaei-Salim F. Distribution of hepatitis C virus genotypes in Iranian chronic infected patients. Hepat Mon. 2013;13(1).

13. Samimi-Rad K, Nasiri Toosi M, Masoudi-Nejad A, Najafi A, Rahimnia $\mathrm{R}$, Asgari F, et al. Molecular epidemiology of hepatitis $\mathrm{C}$ virus among injection drug users in Iran: a slight change in prevalence of HCV genotypes over time. Arch Virol. 2012;157(10):1959-65.

14. Bokharaei-Salim F, Keyvani H, Zamani F, Jahanbakhsh Sefidi F, Amiri A. [Investigating the presence of different hepatitis $C$ virus genotypes in serum, peripheral blood mononuclear cells, and liver biopsy specimens of patients with hepatitis $C$ virus infection]. Tehran Univ Med J. 2012;69(10):624-30.

15. Bokharaei-Salim F, Keyvani H, Monavari SH, Alavian SM, Madjd Z, Toosi MN, et al. Occult hepatitis C virus infection in Iranian patients with cryptogenic liver disease. J Med Virol. 2011;83(6):98995.

16. Bokharaei Salim F, Keyvani H, Amiri A, Jahanbakhsh Sefidi F, Shakeri R, Zamani F. Distribution of different hepatitis $C$ virus genotypes in patients with hepatitis $C$ virus infection. World $J$ Gastroenterol.2010;16(16):2005-9.

17. Sharifi Z, Shooshtari MM, Kermani FR. Identification of HCV genotypes in HCV infected blood donors. Indian J Microbiol. 2010;50(3):275-9.

18. Keshvari M, Alavian SM, Behnava B, Miri SM, Elizee PK, Tabatabaei $\mathrm{SV}$, et al. Distribution of hepatitis $\mathrm{C}$ virus genotypes in iranian patients with congenital bleeding disorders. Iran Red Crescent Med J. 2010;12(6):608-14.

19. Mohammad Alizadeh AH, Keyvani H, Alavian S, Ranjbar M. [Frequency of hepatitits $C$ virus genotypes in chronic hepatitis C patients in Tehran, 2003-2005]. Iran J Infect Dis Trop Med. 2008;13(40):15-9.

20. Keyvani H, Alizadeh AH, Alavian SM, Ranjbar M, Hatami S. Distribution frequency of hepatitis $\mathrm{C}$ virus genotypes in 2231 patients in Iran. Hepatol Res. 2007;37(2):101-3.

21. Zali MR, Mayumi M, Raoufi M, Nowroozi A. Hepatitis $C$ virus genotypes in the Islamic Republic of Iran: a preliminary study. East Mediterr Health J. 2000;6(2-3):372-7.

22. Hosseini-Moghaddam SM, Keyvani H, Kasiri H, Kazemeyni SM, Basiri A, Aghel N, et al. Distribution of hepatitis $C$ virus genotypes among hemodialysis patients in Tehran--a multicenter study. $J$ Med Virol. 2006;78(5):569-73.

23. Ahmadi Pour MH, Keivani H, Sabahi F, Alavian SM. Determination of HCV Genotypes, in Iran by PCR-RFLP. Iranian J Publ Health. 2006;35(4):54-61.

24. Kazemi B. Determination of HCV genotypes in Iran. Biotecnol. 2005;4(2):139-43.

25. Vossughinia H, Goshayeshi L, Bayegi HR, Sima H, Kazemi A, Erfani S, et al. Prevalence of Hepatitis C Virus Genotypes in Mashhad, Northeast Iran. Iran J Public Health. 2012;41(9):56-61.

26. Sarvghad M, Bejadi A, Farrokhneia M, Javanian M. [Study of hepatitis c virus genotypes in patients with chronic hepatitis in Mashhad]. Med J Mashad Univ Med Sci. 2006;49(93):309-14.

27. Vahdat K, Amini A, Moatamed N, Eghbali S, Zandi K, Hajeiani G [Determination of Hepatit $\mathrm{C}$ genotype and risk factors of transmission in Bushehr province 2008]. Iranian South Med. 2012;1:51-7. 
28. Vahdat K, Keyvani H, Tabib SM, Rostamabadi S, Valizadeh SM Cheraghi S, et al. Molecular epidemiology of hepatitis C virus genotypes in Bushehr province, Iran. Eur Rev Med Pharmacol Sci. 2010;14(10):861-4.

29. Nazemi A, Tazehabadi ES, Jafarpoor M, Sharifi S. A Novel and Simple Method for HCV Genotyping. Int J Mol and Clin Microbiol. 2011;1.

30. Joukar F, Khalesi AK, Jafarshad R, Rahimabadi MS, MansourGhanaei F. Distribution of hepatitis $C$ virus genotypes in haemodialysis patients of Guilan, northern Islamic Republic of Iran. East Mediterr Health J. 2012;18(3):236-40.

31. Jafroodi M, Asadi R, Heidarzadeh A. [Evaluation of Correlation between Iron over Load and the Response of Chronic Hepatitis $\mathrm{C}$ in Thalassemia Major Patients Treat with Alfa- Interferon and Ribavirin]. J Guilan Univ Med Sci. 2010;18(72):8-15.

32. Ghane M, Eghbali M, Nejad HR, Saeb K, Farahani M. Distribution of hepatitis $C$ virus genotypes amongst the beta-thalassemia patients in North of Iran. PakJ Biol Sci. 2012;15(15):748-53.

33. Rafiei A, Darzyani AM, Taheri S, Haghshenas MR, Hosseinian A Makhlough A. Genetic diversity of HCV among various high risk populations (IDAs, thalassemia, hemophilia, HD patients) in Iran. Asian Pac J Trop Med. 2013;6(7):556-60.

34. Haghshenas M, Babamahmoodi F, Rafiee A, Vahedi V. . [The Correlation between HCV Genotypes and Liver Damage in HCV Patients]. J Mazand Univ Med Sci. 2011;21(85):76-83.

35. Makhloogh A, Aezinia N, Haghshenas M, Tirgar fakheri H, Maleki I, Taghvaei T. [Comparison of Hepatitis C Virus Genotypes in Hemodialysis and Nonuremic Patients]. Armaghane-danesh. 2009;15(3):283-92.

36. Assarehzadegan MA, Ghafourian Boroujerdnia M, Zandian K. Prevalence of hepatitis B and C infections and HCV genotypes among haemophilia patients in ahvaz, southwest iran. Iran Red Crescent Med J. 2012;14(8):470-4.

37. Farshadpour F, Makvandi M, Samarbafzadeh AR, Jalalifar MA. Determination of hepatitis $C$ virus genotypes among blood donors in Ahvaz, Iran. Indian J Med Microbiol. 2010;28(1):54-6.

38. Assarehzadegan M, Shakerinejad G, Norouzirad R, Amini A. [Distribution of hepatitis $C$ virus genotypes among patients with hepatitis C infection in Khuzestan province]. Jundishapur Sci Med J. 2009;7(4):471-9.

39. Tajbakhsh E, Dosti A, Tajbakhsh S, Momeni M, Tajbakhsh F. Determination of hepatitis $\mathrm{C}$ virus genotypes among HCV positive patients in Shahrekord, Iran. Afr J Microbiol Res. 2011;5(32):5910-5.

40. Ziyaeyan M,Alborzi A, Badiee P, Moeini M. Prevalence of hepatitis $C$ virus genotypes in chronic infected patients, southern Iran. Jundishapur J Microbiol. 2011;4(3):141-6.

41. Davarpanah MA, Bagheri Lankarani K, Mehrabani D, Behzad Behbahani A, Serati A, Ardebili M, et al. Hepatitis C virus genotype distribution in Shiraz, southern Iran. Hepat Mon. 2009;9(2):122-7.

42. Bafandeh Y SFMBLK. [Evaluation of combination therapy with Interferon and Ribavirin in patients with chronic hepatitis C: A genotype based study].J Mazandaran Univ Med Sci. 2007;17(57):9-16.

43. Farivar TN, Nezam MK, Johari P. Genotyping of hepatitis C virus isolated from hepatitis patients in Southeast of Iran by Taqman Realtime PCR.J Pak Med Assoc. 2011;61(6):586-8.

44. Shahraki T, Shahraki M, Moghaddam ES, Najafi M, Bahari A. Determination of hepatitis $C$ genotypes and the viral titer distribution in children and adolescents with major thalassemia. Iran J
Pediatr. 2010;20(1):75-81.

45. Molaabedin M, Pedarzadeh M. [Study of Various HCV Genotypes in Patients Managing by Referral Clinic in Yazd Province]. J Shahid Sadoughi Univ Med Sci. 2011;19(6):784-90.

46. Zarkesh-Esfahani SH, Kardi MT, Edalati M. Hepatitis C virus genotype frequency in Isfahan province of Iran: a descriptive crosssectional study. Virol J. 2010;7:69.

47. Moradi A, Semnani S, Keshtkar A, Khodabakhshi B, Kazeminejad V, Molana A. [Distribution of Hepatitis C Virus Genotype among HCV Infected Patients in Golestan Province, Iran]. Govaresh. 2010;15(1):7-13

48. Hajia M, Amirzargar A, Khedmat H, Shahrokhi N, Farzanehkhah M, Ghorishi S, et al. Genotyping Pattern among Iranian HCV Positive Patients. Iran J Public Health. 2010;39(2):39-44.

49. Kabir A, Alavian SM, Keyvani H. Distribution of hepatitis C virus genotypes in patients infected by different sources and its correlation with clinical and virological parameters: a preliminary study. Comp Hepatol. 2006;5:4.

50. Amini S, Mahmoodi Farahani Majd Abadi M, Alavian S, Joulaie M, Ahmadipour M. Distribution of hepatitis C virus genotypes in Iran: a population-based study. Hepat Mon. 2009;9(2):95-102.

51. Alavian SM, Miri SM, Keshvari M, Elizee PK, Behnava B, Tabatabaei SV, et al. Distribution of hepatitis C virus genotype in Iranian multiply transfused patients with thalassemia. Transfusion. 2009;49(10):2195-9.

52. Somi MH, Keivani H, Ardalan MR, Farhang S, Pouri AA. Hepatitis $C$ virus genotypes in patients with end-stage renal disease in East Azerbaijan, Iran. Saudi J Kidney Dis Transpl. 2008;19(3):461-5.

53. Omrani M, Khadem Ansari M. Hepatitis c virus genotyping by melting curve analysis in west azerbaijan, northwest of IRAN Hepat Mon. 2009;9(2):133-6.

54. Sharifi Z, Mahmoudian Shooshtari M. Hepatitis $C$ virus infection and genotypes in blood donors. Iran JVirol. 2008;2(4):17-22.

55. Samimi-Rad K, Nategh R, Malekzadeh R, Norder H, Magnius L. Molecular epidemiology of hepatitis $C$ virus in Iran as reflected by phylogenetic analysis of the NS5B region. J Med Virol. 2004;74(2):246-52.

56. Samimi-Rad K, Hosseini M. Hepatitis C virus infection and hcv genotypes of hemodialysis patients. Iranian J Publ Health. 2008;37(3):146-52.

57. Samimi-Rad K, Shahbaz B. Hepatitis C virus genotypes among patients with thalassemia and inherited bleeding disorders in Markazi province, Iran. Haemophilia. 2007;13(2):156-63.

58. Zahedi M, Darvish Moghadam S, Hayatbakhsh M, Arabzadeh S, Yazdani V. Prevalence of common Hepatitis C Virus genotypes and relation between age, sex and transmission risk factors in Kerman, southeast of Iran. Iranian J Virology. 2007;1(2):15-9.

59. Afsharian M, Raofi R, Vasiri S, Jahanbaksh AR, Mansouri F, Ghadiri K. Study of Hepatitis C genotype in Cina Hospital, Kermanshah, Iran (in Persian). Iran J Infect Dis Trop Med. 2007;12:19-23.

60. Salehi Moghadam F, Mohebbi SR, Hosseini SM, Romani S, Mirtalebi H, Azimzadeh P, et al. Phylogenetic analysis of hepatitis $C$ virus strains and risk factors associated with infection and viral subtypes among Iranian patients. J Med Virol. 2014;86(8):1342-9.

61. Zamani F, Sohrabi M, Poustchi H, Keyvani H, Saeedian FS, Ajdarkosh $\mathrm{H}$, et al. Prevalence and risk factors of hepatitis $\mathrm{C}$ virus infection in amol city, north of iran: a population-based study (20082011). Hepat Mon. 2013;13(12). 